\title{
Composite Superabsorbent Hydrogel of Acrylic Copolymer and Eggshell: Effect of Biofiller Addition
}

\author{
Marcos Vinícius A. Queirós, Maslândia N. Bezerra and Judith P. A. Feitosa* \\ Departamento de Química Orgânica e Inorgânica, Laboratório de Polímeros, \\ Universidade Federal do Ceará, C. P. 6021, 60455-760 Fortaleza-CE, Brazil
}

\begin{abstract}
Eggshell (ES) is an abundant waste material which is mainly composed of calcium carbonate. A superabsorbent hydrogel composite based on poly(acrylamide-co-potassium acrylate) as matrix containing $17 \mathrm{wt} . \%$ of chicken ES powder as a filler was synthesized and compared with the gel without filler. The characterization was carried out by Fourier transform infrared (FTIR), scanning electron microscopy with energy dispersive X-ray spectroscopy (SEM/EDX), thermogravimetric analysis (TGA), X-ray diffraction (XRD), rheological analysis and kinetics studies. The dispersion of ES in the polymeric matrix was homogeneous. The interaction between the acrylate and calcium cation was detected by FTIR analysis. The composite improved the gel strength and the absorption of water and saline solution increased by 100 and $41 \%$, respectively. The high values for the swelling, the homogeneous structure and the good mechanical properties obtained with the incorporation of a relatively high content of a low-cost waste material indicate that this composite is suitable for application in the agriculture. In addition, this approach provides a more ecologically sound and useful destination for eggshell residue.
\end{abstract}

Keywords: polymer-matrix composite, superabsorbent hydrogel, acrylamide, acrylate, eggshell

\section{Introduction}

Water management is in a state of crisis since there are currently more than one billion people who do not have access to safe drinking water. In addition, water resources have been shown to be insufficient to produce food in many countries. Irrigation accounts for around $70 \%$ of the total anthropogenic water use, corresponding to 2,500 out of $3,800 \mathrm{~km}^{3} .^{1}$ In arid and semi-arid regions, where water supplies are limited, agricultural practices increase the water consumption resulting in the degradation of natural ecosystems. ${ }^{2}$

In view of these problems, coupled with a growing population and a subsequent increase in food demand, the development of new technologies is necessary for the efficient use of water for agriculture. Superabsorbent polymers (SAPs), also known as hydrogels, have been used in recent years as an alternative to improve the management of water use in agricultural operations. ${ }^{3}$ Hydrogels are cross-linked materials which are able to absorb and retain large amounts of water (many times their weight). They increase the water retention properties of growing media and plant growth. ${ }^{4}$ SAPs are applied in soil as granules.

*e-mail: judith@dqoi.ufc.br
After watering, the granules swell and release the water slowly when the soil gets dry. The plant roots absorb water efficiently, and the loss of water through drainage or evaporation is avoided. Another advantage of SAPs is that nutritional substances can be incorporated into them and subsequently released gradually to the plants. ${ }^{5}$

Most commercial SAPs used in agriculture are pure polymers based on acrylics, normally copolymers of acrylamide and acrylate. The current trend is to add minerals to the copolymers in order to obtain a superabsorbent hydrogel composite. ${ }^{6,7}$ The addition of low-cost minerals decreases the price, enhances the mechanical properties, increases water absorption and reduces the effect of salt. ${ }^{6-8}$ Many researchers have studied the incorporation of waste material and clays, such as bentonite, ${ }^{6,8}$ nontronite, ${ }^{7}$ dolomite, ${ }^{8}$ laponite ${ }^{9}$ and rice husk ash,${ }^{10}$ into hydrogels.

In a study reported in the literature, hydrogel composites with dolomite provided an increase of $48 \%$ in the swelling equilibrium. ${ }^{8}$ The used dolomite was composed of $73.7 \%\left(\mathrm{~m} \mathrm{~m}^{-1}\right)$ calcium and magnesium carbonate $\left[\left(\mathrm{CaMg}\left(\mathrm{CO}_{3}\right)_{2}\right]\right.$ and $26.3 \%$ calcium carbonate $\left(\mathrm{CaCO}_{3}\right)$. Carbonates seem to improve the properties of superabsorbent hydrogels based on poly(acrylamide-co-acrylate). Eggshell (ES) is composed mainly of calcium carbonate, 
and thus its addition to hydrogels should provide an increase in water absorption. ${ }^{11}$ A comparison between the effects of eggshell and dolomite on the swelling of superabsorbents can be correlated with the effects of calcium carbonate or magnesium carbonate. In addition, the use of eggshell provides an important environmental benefit, reducing the level of a waste material to be discarded by processing it into a useful product.

Eggshell (ES) is one of the most common biomaterials in nature. It is a by-product of the food industry which is normally discarded and disposed of in landfills. In 2013, the global production of eggs was almost 68 million tons. ${ }^{12}$ The shell comprises around $11 \%$ of the total egg weight, and thus ca. 7.48 million tons of ES are generated as waste per year globally, leading to environmental problems. ${ }^{13,14}$ ES is composed of $94 \%$ calcium carbonate, $1 \%$ magnesium carbonate, $1 \%$ calcium phosphate, and $4 \%$ organic materials such as sulfated polysaccharide and collagens. ${ }^{11}$

Despite being treated as a waste, many applications have been studied, mostly considering this material as a rich source of $\mathrm{CaCO}_{3}$. It has been proposed as an advanced and green alternative for a structural material in biocomposites based on epoxy formulations. ${ }^{15}$ In a previous study, eggshell-derived nano- and microscale hydroxyapatite bioceramic bone grafts were synthesized. ${ }^{16}$ ES has also been tested as a heterogeneous base catalyst for biodiesel production from used cooking oil. ${ }^{17}$ In addition, ES has been successfully used for the removal of heavy metal ions $\left(\mathrm{Ag}^{\mathrm{I}}\right.$, $\mathrm{Cd}^{\mathrm{II}}$ and $\mathrm{Zn}^{\mathrm{II}}$ ) from model solutions, ${ }^{18}$ and $\mathrm{Cr}^{\mathrm{III}}$ from chrome tanning wastewater. ${ }^{19}$ The co-composting of ES provides an effective liming material which can also be used for the in situ remediation of soils contaminated with $\mathrm{Pb}$ and $\mathrm{Zn} .{ }^{20}$ Due to its high thermal stability and mechanical properties, ES has been proposed as a novel biofiller for intumescent flame-retardant coatings. ${ }^{21}$

In this study, chicken eggshell powder was used as a source of calcium carbonate $\left(\mathrm{CaCO}_{3}\right)$ in the synthesis of a superabsorbent hydrogel composite from poly(acrylamideco-potassium acrylate). The effect of the addition of eggshell to the copolymer was evaluated by comparing the swelling kinetics of the copolymer (Pam-Ac) and the composite (Pam-Ac/ES) in distilled water. The behavior of the hydrogels was also investigated in salt solution.

\section{Experimental}

Reagents

Acrylamide (Am), potassium persulfate (KPS) and $N, N, N^{\prime}, N^{\prime}$-tetramethylethylenediamine (TEMED) were obtained from Merck. $N, N^{\prime}$-Methylenebisacrylamide
(MBA) was purchased from Sigma-Aldrich and acrylic acid (AA) from Vetec. The degree of purity for both Am and AA was higher than $99 \%$. The acrylic acid was neutralized with $\mathrm{KOH}$ until $\mathrm{pH} 7.0$ in an ice bath to prepare potassium acrylate (KAc). White chicken eggs were obtained from a local store. The shells were washed, sanitized with $\mathrm{NaClO}$ solution, oven-dried, grated using a stainless steel sieve (Bertel Indústria Metalúrgica Ltda) and separated into three different size fractions. The fraction with a particle size of smaller than $45 \mu \mathrm{m}$ (325 mesh sieve) was employed in this study. Distilled water was used in all of the experiments.

\section{Synthesis of hydrogels}

The hydrogels were synthesized by free-radical copolymerization following the procedure reported by Magalhães et al. ${ }^{22}$ with a few modifications. Acrylamide (1.05 g, $0.015 \mathrm{~mol}$, in $1 \mathrm{~mL}$ ) was added to $24 \mathrm{~mL}$ of distilled water constantly bubbled with nitrogen. After dissolution, obtained with stirring, aqueous $\mathrm{KAc}\left(3 \mathrm{~mL}, 5 \mathrm{~mol} \mathrm{~L}^{-1}\right.$, $0.015 \mathrm{~mol})$ was added. MBA $(0.2 \mathrm{~mol} \%$ in $1 \mathrm{~mL}$ related to the total number of mols of monomers), KPS ( $0.2 \mathrm{~mol} \%$ in $1 \mathrm{~mL})$ and TEMED $(0.1 \mathrm{~mol} \%)$ were then also added. The total volume was maintained at $30 \mathrm{~mL}$. The system was kept under further stirring until it reached the gel point. After $24 \mathrm{~h}$, the hydrogel was grated, washed and dried in an oven at $70{ }^{\circ} \mathrm{C}$. The material was sieved in order to obtain samples with particle sizes in the range of 500 to $710 \mu \mathrm{m}$ (24-35 mesh). The obtained hydrogel was named Pam-Ac.

The appropriate amount of eggshell in the hydrogel was defined after an initial screening in which the content of the additive was varied from 9 to $33 \%$ (wt.\%), with increments of $4 \%$. The degree of swelling in water was determined and the highest value was obtained for the hydrogel containing $17 \%$ of eggshell. Thus, this percentage of ES was employed in the study. The hydrogel with eggshell powder (named Pam-Ac/ES) was synthesized applying the procedure described above for the hydrogel without filler, with some modifications. An aqueous suspension $(24 \mathrm{~mL})$ of eggshell powder $(0.534 \mathrm{~g})$ was stirred for $24 \mathrm{~h}$ in order to disaggregate the material. The co-monomers were added to this suspension and the above-described procedure was followed. The total volume was maintained at $30 \mathrm{~mL}$. The particle size was the same as that of the hydrogel without addiction of minerals $(500-710 \mu \mathrm{m})$.

\section{Elemental microanalysis}

The contents of carbon, hydrogen and nitrogen were obtained by elemental microanalysis using a Carlo Erba EA 1108 analyzer. 


\section{X-ray diffraction (XRD) analysis}

The XRD analysis of the eggshell powder was carried out on a PANalytical diffractometer (model XPert Pro MPD), with $\mathrm{Cu} \mathrm{K} \alpha$ radiation, with $2 \theta$ varying from $10^{\circ}$ to $70^{\circ}$. The material was sieved and only the particles that passed through a 325 mesh $(<45 \mu \mathrm{m})$ were selected for analysis.

Infrared spectroscopy studies

The Fourier transform infrared (FTIR) spectra for dried samples of Pam-Ac and Pam-Ac/ES were recorded with a Shimadzu IR spectrophotometer (model FT IR-8500) in the range of 400 to $4000 \mathrm{~cm}^{-1}$ using $\mathrm{KBr}$ pellets.

\section{Thermogravimetric analysis (TGA)}

The thermal degradation behavior was monitored using a TA Instruments thermogravimetric analyzer (model TGA-Q50). The samples (2.5-3.5 $\mathrm{mg}$ ) were placed in a platinum pan and heated to $1000{ }^{\circ} \mathrm{C}$ using a $10{ }^{\circ} \mathrm{C} \mathrm{min}{ }^{-1}$ heating ramp in a synthetic air environment with an air flow of $50 \mathrm{~cm}^{3} \mathrm{~min}^{-1}$. The particles which passed through a 45 mesh sieve were subject to analysis.

\section{Scanning electron microscopy (SEM)}

Surface images of the eggshell and hydrogels were obtained on an Inspect S50 scanning electron microscope coupled to an energy dispersive X-ray spectrometer (SEM-EDX). Small slices of samples, swollen in distilled water until equilibrium, were frozen with liquid nitrogen, dried by freeze-drying and coated with gold prior to the analysis.

\section{Rheology: dynamic tests}

Rheological measurements were performed using a TA Instruments rheometer (model AR550) with parallel plate geometry and with a plate diameter of $20 \mathrm{~mm}$ at $25^{\circ} \mathrm{C}$. The measurements were taken using the previously synthesized hydrogels. To obtain the materials, synthesis was carried out following the method described above, but a test-tube was used instead of a reactor to obtain cylindrical gels with the same diameter $(20 \mathrm{~mm})$. After synthesis, the hydrogels were left to stand for $24 \mathrm{~h}$. The test-tube was then broken and the gel was cut into cylindrical shapes with a height of $0.5 \mathrm{~cm}$. The oscillatory measurements were carried out at a frequency range of 0.1-1.5 Hz.
Degree of swelling in distilled water

The swelling kinetics of Pam-Ac and Pam-Ac/ES in distilled water at $25 \pm 1{ }^{\circ} \mathrm{C}$ were compared. A known mass of gel (approximately $20 \mathrm{mg}$ ) was placed inside a pre-weighed sintered glass-filter (No. 0) and covered with distilled water at room temperature. The glass filter was then removed and the excess water was drained. The external walls were dried and the system was re-weighed. Initially, the systems were weighed at intervals of $1.0 \mathrm{~min}$, and then at longer intervals. The degree of swelling was determined according to equation 1 :

$\mathrm{W}_{\mathrm{eq}}=\left(\mathrm{m}_{\mathrm{sw}}-\mathrm{m}_{\mathrm{dr}}\right) / \mathrm{m}_{\mathrm{dr}}$

where $\mathrm{W}_{\mathrm{eq}}$ is the equilibrium degree of swelling, $\mathrm{m}_{\mathrm{sw}}$ is the mass of swollen material and $\mathrm{m}_{\mathrm{dr}}$ is the mass of the dried material.

\section{Swelling in salt solution}

The behavior of the hydrogels in a solution designed to simulate soil conditions was also investigated at $25 \pm 1{ }^{\circ} \mathrm{C}$. The materials were immersed in a salt solution with a composition of $\mathrm{NaCl}\left(0.2 \mathrm{mmol} \mathrm{L}^{-1}\right), \mathrm{KCl}\left(0.2 \mathrm{mmol} \mathrm{L}^{-1}\right)$, $\mathrm{MgCl}_{2}\left(0.2 \mathrm{mmol} \mathrm{L}^{-1}\right)$ and $\mathrm{CaCl}_{2}\left(0.3 \mathrm{mmol} \mathrm{L}^{-1}\right)^{23-25}$ and the swelling was determined as described above.

\section{Results and Discussion}

\section{Characterization of the chicken eggshell powder}

The diffraction pattern for the eggshell powder shown in Figure 1 was compared with the calcite pattern calculated from ICSD data using POWD-12++. The most intense peak at a $2 \theta$ value of $29.5^{\circ}$ corresponds to the $\{104\}$ plane of calcite. ${ }^{15}$ The two powder diffraction patterns show good agreement. The chemical composition of the eggshell obtained by XRF showed a large amount of calcium $(99.09 \pm 0.29 \%)$ followed by very low amounts of phosphorous $(0.26 \pm 0.04 \%)$, probably present as calcium phosphate and sulfur $(0.28 \pm 0.04 \%)$ associated with sulfated polysaccharides. ${ }^{14}$

The TGA and differential thermogravimetry (DTG) curves for the eggshell are shown in Figure 2. A very small decrease in mass can be observed between 226 and $574{ }^{\circ} \mathrm{C}$ due to the decomposition of residual organic matter. The main event takes place within the temperature range of 574-731 ${ }^{\circ} \mathrm{C}$ and is attributed to thermal decomposition of $\mathrm{CaCO}_{3}$ with the release of $\mathrm{CO}_{2}$. The residue at $800{ }^{\circ} \mathrm{C}$ $(52.8 \%)$ refers to inorganic compounds, in this case $\mathrm{CaO} .{ }^{26}$ 


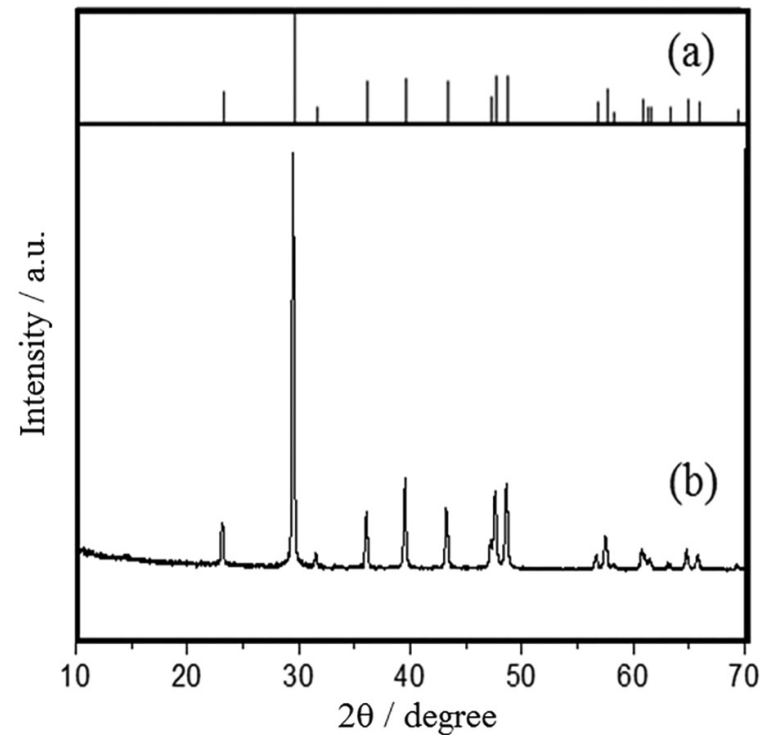

Figure 1. X-ray profiles for (a) calcite and (b) eggshell (reference code 85-1108).

This value is close to that of the residue of pure $\mathrm{CaCO}_{3}$ shown in the figure (55.9\%). The $\mathrm{CaCO}_{3}$ content was determined through the loss of $\mathrm{CO}_{2}$ in the third stage by stoichiometric calculations, giving a value of $94.4 \%$, which is in agreement with the value of $94 \%$ reported in the literature. ${ }^{14}$

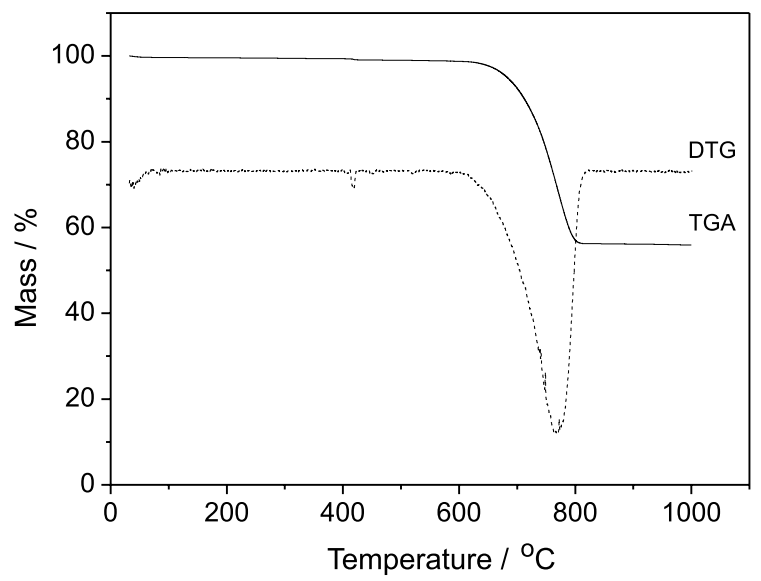

Figure 2. TGA/DTG curves for eggshell powder.

\section{Characterization of hydrogels}

\section{Infrared spectroscopy studies}

The FTIR spectra for Pam-Ac, ES and the Pam-Ac/ES composite can be observed in Figure 3, and the assignments are shown in Table 1. Peaks due to the carbonate vibration modes are present at $1421 \mathrm{~cm}^{-1}\left(\mathrm{~V}_{3}\right), 876 \mathrm{~cm}^{-1}\left(\mathrm{~V}_{2}\right)$ and $713 \mathrm{~cm}^{-1}\left(v_{4}\right)$, as indicated on the eggshell spectrum. A shoulder appears at $1084 \mathrm{~cm}^{-1}\left(v_{1}\right)$, which is attributed to the symmetric stretching of $\mathrm{CO}_{3}{ }^{-28}$ Two other bands are related to combination bands, that is $v_{1}+v_{4}$ at $1801 \mathrm{~cm}^{-1}$ and $v_{1}+v_{3}$ at $2518 \mathrm{~cm}^{-1}$. Bands associated with adsorbed water were also observed at 3380 and $1643 \mathrm{~cm}^{-1}$. The presence of organic material can be deduced from the appearance of a band in the region of 2924-2867 $\mathrm{cm}^{-1}$. In the Pam-Ac spectrum, the important bands are those at $1675 \mathrm{~cm}^{-1}(\mathrm{C}=\mathrm{O}$ from acrylamide), $1568 \mathrm{~cm}^{-1}$ ( $\mathrm{v}_{\text {as }} \mathrm{COO}^{-}$from acrylate) and $1399 \mathrm{~cm}^{-1}\left(\mathrm{v}_{\mathrm{s}} \mathrm{COO}^{-}\right.$from acrylate). Similar bands can be observed on the Pam-Ac/ES spectrum. The difference between $v_{\text {as }} \mathrm{COO}^{-}$and $v_{\mathrm{s}} \mathrm{COO}^{-}$could be related to the metal-carboxylate interaction. ${ }^{29} \mathrm{~A}$ comparison was made between free $\Delta v\left(\mathrm{COO}^{-}\right)$and $\Delta v\left(\mathrm{COO}^{-}\right)$bound to di- or trivalent cations. The carboxylate of the copolymer interacts with the $\mathrm{Ca}^{2+}$ of the eggshell calcite. The values obtained for $\Delta v$ were $\Delta v\left(\mathrm{COO}^{-}\right)_{\mathrm{K}}$ in Pam-Ac $170 \mathrm{~cm}^{-1}$ and $\Delta v\left(\mathrm{COO}^{-}\right)_{\mathrm{Ca}}$ in Pam-Ac/ES $147 \mathrm{~cm}^{-1}$. The decrease in $\Delta v$ indicates the coordination of metal cations to the carboxylate, which verifies the calcite-acrylate interaction. A similar trend was observed for $\mathrm{Ca}^{2+}$-alginate, in which the difference in $\Delta v$ was $13 \mathrm{~cm}^{-1} .{ }^{29}$ This difference was higher for Pam-Ac/ES $\left(23 \mathrm{~cm}^{-1}\right)$, confirming the $\mathrm{Ca}^{2+}-\mathrm{COO}^{-}$or eggshell powdercopolymer interaction.

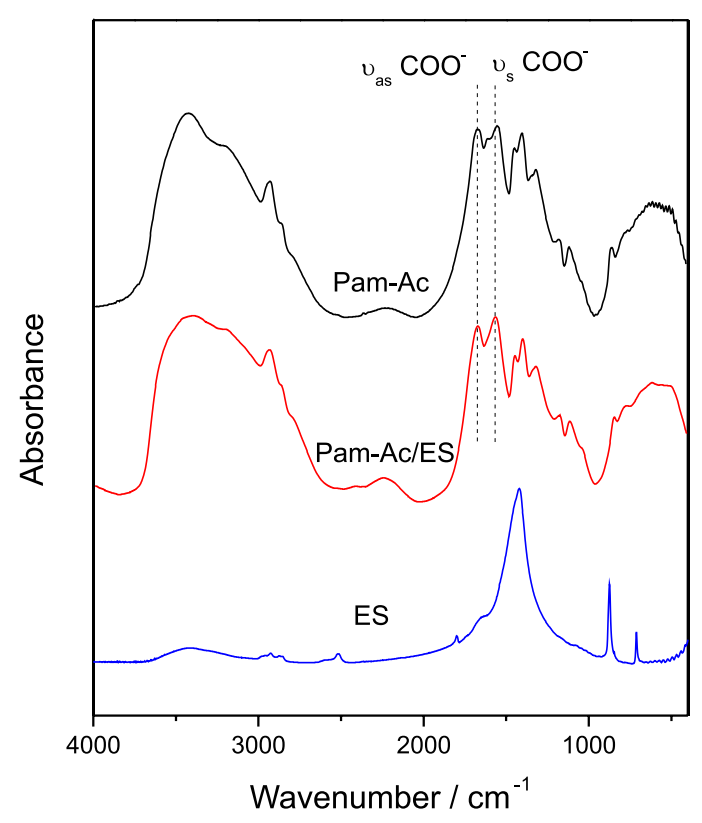

Figure 3. FTIR spectra for eggshell powder (ES) and hydrogels.

\section{Elemental microanalysis}

The results for the chemical analysis of Pam-Ac and Pam-Ac/ES are given in Table 2. Considering that all of the nitrogen content originates from the acrylamide monomeric unit $\left[-\mathrm{CH}\left(\mathrm{CONH}_{2}\right) \mathrm{CH}_{2}-\right]$, the mols of $\mathrm{Am}$ in $100 \mathrm{~g}$ of hydrogel $(\% \mathrm{~mol} \mathrm{Am})$ can be calculated. Acrylamide and $\mathrm{K}$ acrylate $\left[-\mathrm{CH}(\mathrm{COOK}) \mathrm{CH}_{2}-\right]$ contain carbon. On determining the carbon associated with acrylamide, the mols of acrylate in $100 \mathrm{~g}$ of hydrogel (\%mol KAc) can be 
Table 1. Assignments of the main bands of the FTIR spectra for eggshell (ES), and for hydrogels Pam-Ac and Pam-Ac/ES

\begin{tabular}{|c|c|c|c|}
\hline \multirow{2}{*}{ ES } & \multicolumn{2}{|c|}{ Hydrogel } & \multirow{2}{*}{ Assignment ${ }^{22,27,28}$} \\
\hline & Pam-Ac & Pam-Ac/ES & \\
\hline- & 3427 & 3413 & $\mathrm{v}_{\mathrm{as}} \mathrm{NH}_{2}$ of acrylamide unit \\
\hline 3380 & 3219 & 3219 & vOH of adsorbed water \\
\hline- & 3195 & - & $v_{\mathrm{s}} \mathrm{NH}_{2}$ of acrylamide unit \\
\hline 2924-2867 & 2933 and 2860 & 2933 and 2857 & $v \mathrm{CH}$ and $v \mathrm{CH}_{2}$ \\
\hline 2516 & - & - & combination band $\mathrm{CO}_{3}^{-}$ \\
\hline 1799 & - & - & combination band $\mathrm{CO}_{3}^{-}$ \\
\hline- & 1670 & 1670 & $v \mathrm{C}=\mathrm{O}$ of acrylamide \\
\hline 1657 & - & - & $\delta \mathrm{OH}$ of water \\
\hline- & 1569 & 1554 & $\mathrm{v}_{\mathrm{as}} \mathrm{COO}^{-}$of K-acrylate \\
\hline 1421 & - & - & $\mathrm{v}_{\mathrm{as}} \mathrm{CO}_{3}^{-}$ \\
\hline- & 1399 & 1407 & $v_{s} \mathrm{COO}^{-}$of $\mathrm{K}$-acrylate and $v \mathrm{CN}$ of acrylamide \\
\hline 878 & - & - & $\delta_{\text {out plane }} \mathrm{CO}_{3}^{-}$ \\
\hline 713 & - & - & $\delta_{\text {in plane }} \mathrm{CO}_{3}^{-}$ \\
\hline
\end{tabular}

calculated. The equations used to determine the molar ratio of Am/KAc in the Pam-Ac hydrogels were

$\% \mathrm{~mol} \mathrm{Am}=\frac{\% \mathrm{~N}}{14}$

$\%$ mol C from $\mathrm{KAc}=\frac{\% \mathrm{C}}{12}-\frac{3 \% \mathrm{~N}}{14}$

$\% \mathrm{~mol} \mathrm{KAc}=\frac{\% \mathrm{~mol} \mathrm{C} \text { from KAc }}{3}=\left(\frac{\% \mathrm{C}}{12}-\frac{3 \% \mathrm{~N}}{14}\right) / 3$

molar ratio of $\frac{\mathrm{Am}}{\mathrm{KAc}}=\frac{\frac{3 \% \mathrm{~N}}{14}}{\frac{\% \mathrm{C}}{12}-\frac{3 \% \mathrm{~N}}{14}}$

In the case of Pam-Ac/ES, the carbon content associated with carbonate can be determined using equation 3 . The percentage (by weight) of eggshell in the hydrogel was 16.7 and the calcium carbonate content in ES was determined as $94.4 \%$. Thus, the calcium carbonate content in $100 \mathrm{~g}$ of hydrogel was $15.8 \%$. The molar mass of $\mathrm{CaCO}_{3}$ is $100 \mathrm{~g} \mathrm{~mol}^{-1}$. Therefore

$$
\begin{aligned}
& \% \mathrm{~mol} \mathrm{C} \text { from ES carbonate }= \\
& \% \mathrm{~mol} \text { of } \mathrm{Ca} \text { carbonate in hydrogel }=\frac{15.8}{100}
\end{aligned}
$$

$\%$ mol C from KAc $=\frac{\% \mathrm{C}}{12}-\frac{3 \% \mathrm{~N}}{14}-0.17$

$$
\text { molar ratio of } \mathrm{Am} / \mathrm{KAc}=\frac{\frac{3 \% \mathrm{~N}}{14}}{\frac{\% \mathrm{C}}{12}-\frac{3 \% \mathrm{~N}}{14}-0.158}
$$

For Pam-Ac, this value was $1.05 \pm 0.18$, very close to the theoretical value (1.00). The Am/KAc value for Pam-Ac/ES was 1.28 \pm 0.05 . Similar results were obtained for Pam-KAc in the absence $(\mathrm{Am} / \mathrm{Kac}=0.96)$ and in the presence $(\mathrm{Am} / \mathrm{Kac}=1.2)$ of $10 \%$ of dolomite. ${ }^{8}$ The higher value in the composite hydrogels is probably related to the lower availability of acrylate due to its complexation with $\mathrm{Ca}^{2+}$ and/or other positively-charged functional groups at the calcite surface. ${ }^{30}$

\section{Thermogravimetric analysis (TGA)}

The thermal decomposition curve for Pam-Ac is shown in Figure 4. Four stages can be observed: the first two stages (323 and $391{ }^{\circ} \mathrm{C}$ ) being attributed to the decomposition of acrylamide units and the other stages to the decomposition of acrylate units $\left(550\right.$ and $883^{\circ} \mathrm{C}$ ). At $1000{ }^{\circ} \mathrm{C}$, the final residue is zero. According to Dassanayake and Phillips, ${ }^{31}$ the thermal decomposition of polyacrylamide occurs at $492{ }^{\circ} \mathrm{C}$ and the thermal decomposition of polyacrylate starts at higher temperatures. In addition, Silva et al. ${ }^{32}$ reported that the thermal degradation of dry polyacrylamide occurs in two stages (at 326 and $410{ }^{\circ} \mathrm{C}$ ). The experimental TGA curve in Figure 4 is similar to those reported by the above cited authors. The Am/KAc mass ratio was calculated from the mass loss of each monomer, giving a value of 1.09. In the TGA curve for Pam-Ac/ES (Figure 4), there is another 
Table 2. Elementary chemical composition of hydrogels Pam-Ac and Pam-Ac/ES obtained from microanalysis

\begin{tabular}{lcccc}
\hline \multirow{2}{*}{ Hydrogel } & \multicolumn{3}{c}{ Composition/wt.\% } & \multirow{2}{*}{ Am/Ac ratio } \\
\cline { 2 - 4 } & $\mathrm{C}$ & $\mathrm{H}$ & $\mathrm{N}$ & $1.05 \pm 0.18$ \\
Pam-Ac & $31.94 \pm 2.53$ & $5.54 \pm 0.04$ & $6.40 \pm 1.01$ & $1.28 \pm 0.05$ \\
Pam-Ac/ES & $31.94 \pm 0.11$ & $5.46 \pm 0.04$ & $6.56 \pm 0.13$ & 0 \\
\hline
\end{tabular}

stage at $550-675{ }^{\circ} \mathrm{C}$ related to the decomposition of the eggshell. As previously described, a high rate of mass loss occurs due to the release of $\mathrm{CO}_{2}$ from $\mathrm{CaCO}_{3}$. At this stage, the real content of mineral in the hydrogel was calculated and the value obtained was $17.2 \mathrm{wt} . \%$, which is close to the expected value (16.5 wt.\% to Pam-Ac/ES).

\section{SEM-EDX analysis}

The SEM analysis of Pam-Ac showed a fibrous surface with pores (Figure 5a). The morphology of the Pam-Ac/ES surface (Figure $5 b$ ) differed from that of the Pam-Ac surface. Pore diameters are smaller and the surface more irregular. Interestingly, crystals with the dimensions of those of ES $(3-9 \mu \mathrm{m})$ were not observed in the composite hydrogel. Thus, it appears that the crystals were well dispersed during the synthesis. The acrylate monomer is well distributed along the surface of the hydrogel, as shown by the K-EDX results. A similar distribution can be observed on the Ca-EDX micrograph.

Rheological experiments were conducted to obtain the linear viscoelastic region in the range of $0-10 \mathrm{~Pa}$ at a fixed frequency of 0.1 and $1.5 \mathrm{~Hz}$. A constant stress of 5.0 Pa was selected to conduct the frequency sweep. The rheological results are given in Figure 6. The storage modulus $\left(G^{\prime}\right)$ values for the Pam-Ac and Pam-Ac/ES hydrogels decreased as the frequency increased. This is due to the fact that the time available was not sufficient for chain disentanglement and relaxation. ${ }^{33}$ The addition of eggshell increased the storage modulus of the Pam-Ac hydrogel. Higher gel strength resulted from the presence of the filler. The loss

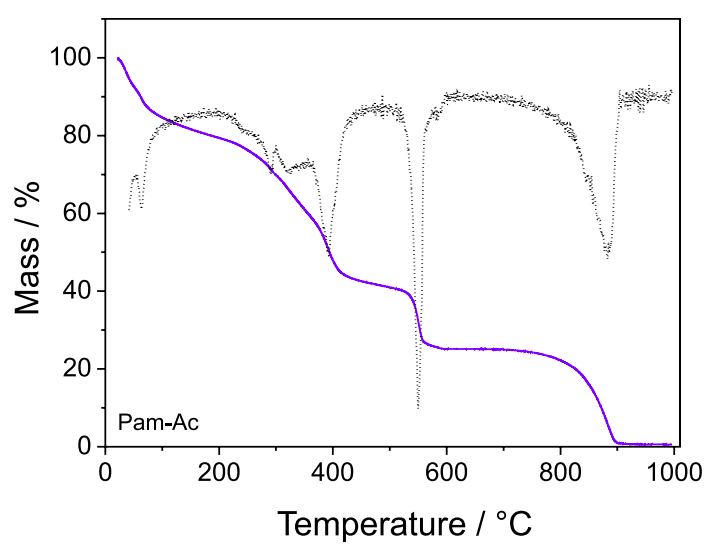

modulus (G") remains almost constant with variations in the frequency and is much lower than the G' values for the two hydrogels. The $\tan \delta$ value calculated from the G'/G' ratio (data not shown) was smaller than 1.0 across the whole frequency range. This indicates an elastic nature or a typical solid-like behavior for both hydrogels.

\section{Swelling kinetics}

The swelling kinetics of Pam-Ac and Pam-Ac/ES can be seen in Figure 7a for water and for the salt solution. In all cases, the swelling rate is higher during the first few minutes and then reaches an equilibrium plateau. A higher degree of swelling was presented by Pam-Ac/ES,

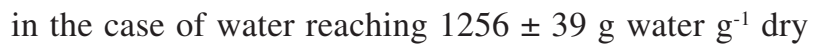
hydrogel. On adding mineral loads to a polymer there is an increase in the hydrophilicity, which leads to a greater difference in the osmotic pressures of the gel and external solution. In the case of water, the degree of swelling for Pam-Ac/ES was around twice that for

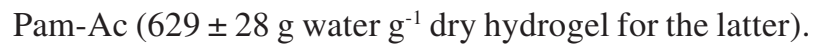
The degree of swelling in water obtained for Pam-Ac/ES in this study is higher than results previously reported for gels containing different minerals, such as bentonite $34 \%,{ }^{6}$ dolomite $52 \%,{ }^{8}$ sepiolite $14-60 \%{ }^{34}$ and nontronite $71 \%{ }^{7}$ The maximum content of mineral in these cited gels was 10 wt.\%. Taking into account the higher content of filler and the fact that eggshell is currently treated as a waste material, the water absorbance capacity of Pam-Ac/ES reported herein is an excellent result.

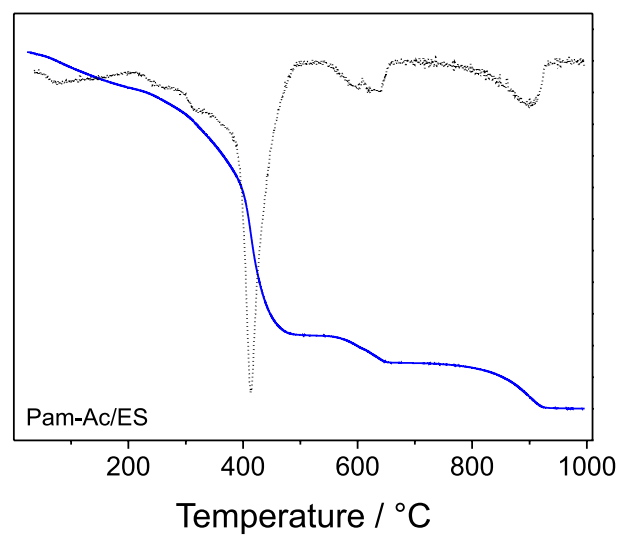

Figure 4. TGA/DTG curves for hydrogels. 

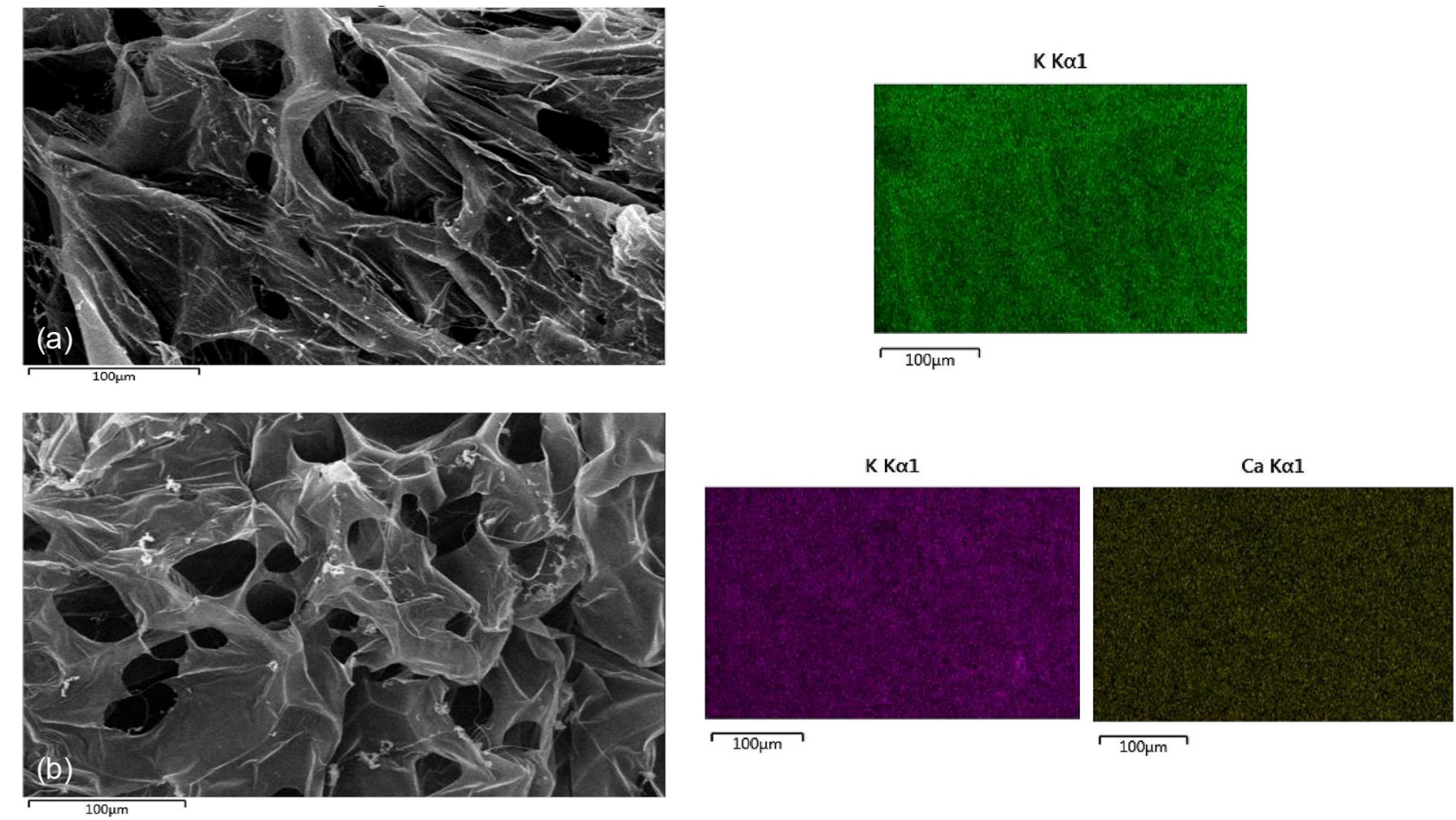

$\longdiv { 1 0 0 \mu \mathrm { m } }$

$\longdiv { 1 0 0 \mu m }$

Figure 5. SEM and EDX images for hydrogels (a) Pam-Ac and (b) Pam-Ac/ES.
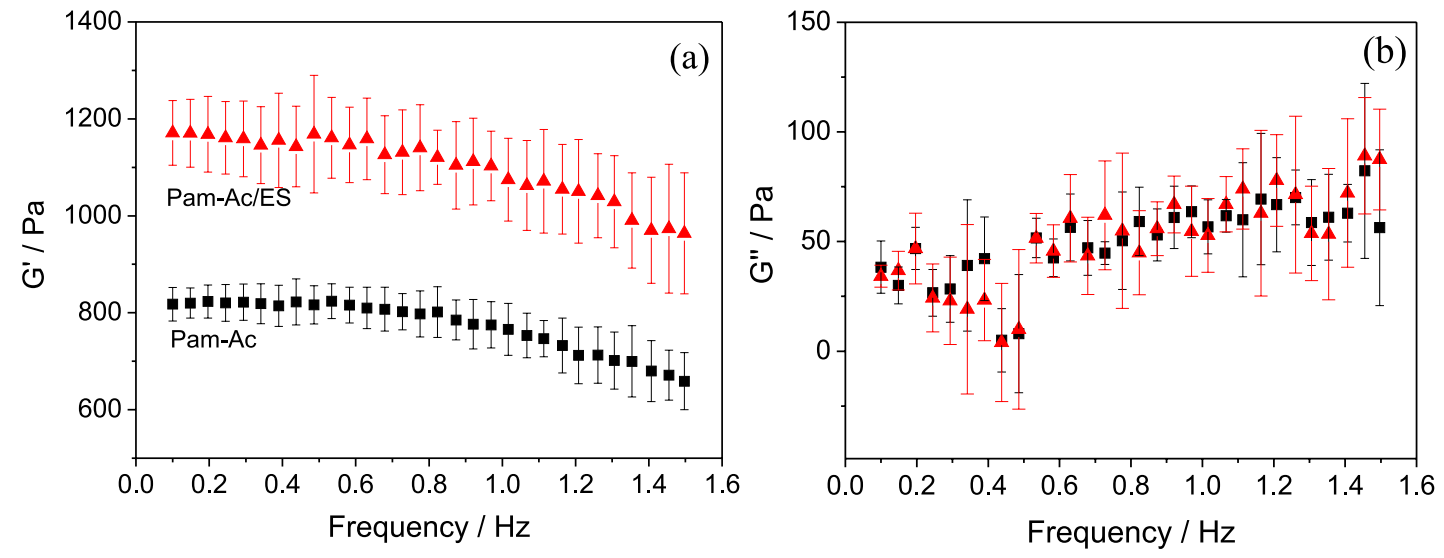

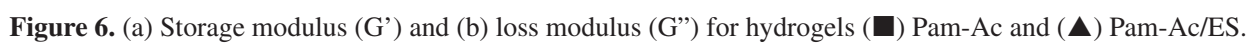
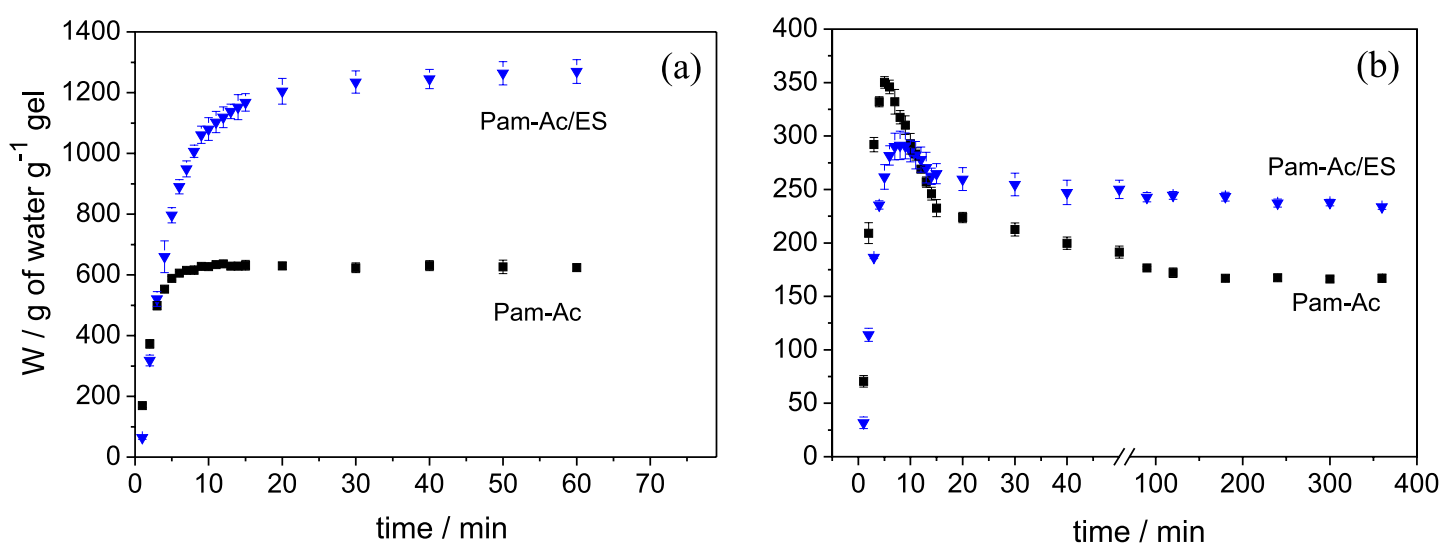

Figure 7. Swelling kinetics plot obtained for hydrogels in (a) distilled water and (b) salt solution. 
An important parameter is the rate constant of swelling. In general, the swelling follows a first-order or a secondorder kinetics. ${ }^{35}$ The second-order rates may be obtained from the well-known equation

$\mathrm{t} / \mathrm{W}=\left[1 / \mathrm{kW}_{\mathrm{eq}}{ }^{2}\right]+\left[1 / \mathrm{W}_{\mathrm{eq}}\right] \mathrm{t}$

where $\mathrm{W}$ is the swelling degree at time $\mathrm{t}, \mathrm{W}_{\mathrm{eq}}$ is the equilibrium swelling degree and $\mathrm{k}$ is a second-order rate constant.

The plot of $\mathrm{t} / \mathrm{W} v s . \mathrm{t}$ is given in Figure 8. It can be observed that almost all of the experimental points lie on the respective straight lines for each hydrogel. However, the values did not fit the straight lines in the first few minutes, suggesting a different kinetics order, probably a first-order process, as suggested by Diez-Peña et al..$^{35} \mathrm{~A}$ new plot (not shown) was obtained without the initial points and a better fit and linear correlation coefficients $\left(\mathrm{R}^{2}\right)$ were observed. The $\mathrm{R}^{2}$ value for the straight line for Pam-Ac increases from 0.9992 to 0.9995 . However, the improvement in $\mathrm{R}^{2}$ is much better for the Pam-Ac/ES hydrogel (0.9738 to 0.9999). Two parameters, $\mathrm{W}_{\mathrm{eq}}$ and $\mathrm{k}$, were calculated from the slope $\left(1 / \mathrm{W}_{\mathrm{eq}}\right)$ and intercept $\left(1 / \mathrm{kW}_{\mathrm{eq}}{ }^{2}\right)$ of the lines and the results are shown in Table 3. The second-order rate constant for Pam-Ac is higher than that for Pam-Ac/ES.

The initial rate constants $\mathrm{k}_{\mathrm{i}}$ were determined from plots of $\ln \left[1-\mathrm{W} / \mathrm{W}_{\mathrm{eq}}\right]$ vs. $\mathrm{t}$ as the slope of the straight lines $\left(-\mathrm{k}_{\mathrm{i}}\right)$ for the swelling of the hydrogels in water. The initial rate

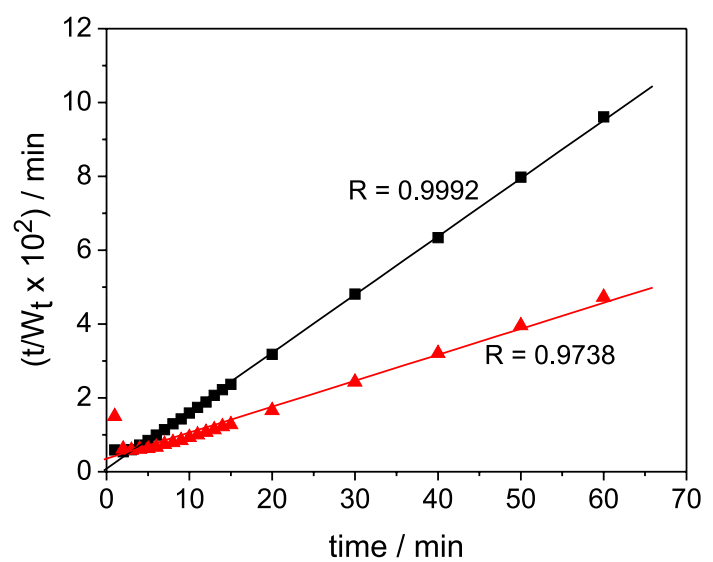

Figure 8. Second-order kinetics plot for swelling of hydrogels: (口) Pam-Ac and (A) Pam-Ac/ES. constants are higher than the second-order rate constants for both hydrogels. The Pam-Ac hydrogel gave the highest rate constant. The experimental data were plotted according to the first-order equation: ${ }^{35}$

$\mathrm{W} / \mathrm{W}_{\mathrm{eq}}=1-\mathrm{e}^{-\mathrm{kt}}$

The swelling degree of the hydrogels was also evaluated in a salt solution aimed at simulating the conditions in soil. The profiles of the swelling curves obtained in salt solution (Figure 7b) differed from those obtained in distilled water. There was a fast absorption of water in the first few minutes followed by mass loss until reaching equilibrium. The curves can be divided into four stages. In the first, the hydrogel swells due to the uptake of water. This is the fastest swelling stage, characterized by an increasing swelling rate. In the second stage, divalent ions are absorbed along with water and the swelling reaches the highest value. In the third stage, there is an exchange between the monovalent ions $\left(\mathrm{Na}^{+}\right.$and $\left.\mathrm{K}^{+}\right)$in the polymeric network and divalent ions in the solution, which coordinate with the carboxylate group in the hydrogel. ${ }^{36}$ In the last stage, the swelling decreases until equilibrium. The swelling of Pam-Ac/ES in the salt solution simulating soil conditions was $41 \%$ higher in comparison with the hydrogel without filler, this performance being better than that previously observed for Pam-Ac/Dol (34\% increase in swelling). ${ }^{8}$

\section{Conclusions}

The incorporation of $17 \mathrm{wt} . \%$ of eggshell waste powder into poly(acrylamide-co-potassium acrylate) improves the absorption of the hydrogel by 100 and $41 \%$ for water and saline solution, respectively, in comparison with the gel without the addition of the waste material. A gel that absorbs an amount of water representing more than 1,000 times its own dry weight was obtained. The dispersion of ES in the polymeric matrix is homogeneous. Interaction between the acrylate in the gel and calcium cation in the eggshell was verified. The composite hydrogel provides a stronger material with a high degree of swelling in water and in salt solution, a homogeneous structure and good mechanical properties. These important advantages, plus the relatively high content

Table 3. Kinetics parameters in distilled water and salt solution simulating soil conditions (SSS)

\begin{tabular}{|c|c|c|c|c|c|}
\hline \multirow{2}{*}{ Hydrogel } & \multicolumn{2}{|c|}{ First-order kinetics in water ${ }^{\mathrm{a}}$} & \multicolumn{3}{|c|}{ Second-order kinetics in water ${ }^{\mathrm{b}}$} \\
\hline & $\mathrm{k}_{\mathrm{i}} / \min ^{-1}$ & $\mathrm{R}^{2}$ & $\mathrm{k} /\left(\mathrm{L} \mathrm{mol} \mathrm{min}^{-1}\right)$ & $\mathrm{W}_{\mathrm{eq}} /\left(\mathrm{g}_{\text {g water }} \mathrm{g}^{-1}\right.$ dry gel $)$ & $\mathrm{R}^{2}$ \\
\hline Pam-Ac & 0.609 & 0.9992 & $5.51 \times 10^{-3}$ & 631 & 0.9995 \\
\hline Pam-Ac/ES & 0.236 & 0.9995 & $3.66 \times 10^{-4}$ & 1314 & 0.9999 \\
\hline
\end{tabular}

${ }^{\mathrm{a}}$ For the first $5 \mathrm{~min}$; ${ }^{\mathrm{b} w i t h o u t ~ t h e ~ f i r s t ~ p o i n t s ; ~} \mathrm{R}^{2}$ : linear correlation coefficient. 
of a low-cost material which would otherwise be treated as a waste material, make Pam-Ac/ES suitable for application in agriculture. In addition, it offers an ecologically sound and widely applicable destination for eggshell residue.

\section{Acknowledgments}

The authors acknowledge financial support from the Brazilian governmental agencies INCT-INOMAT, Conselho Nacional de Desenvolvimento Científico e Tecnológico (CNPq), and Coordenação de Aperfeiçoamento de Pessoal de Nível Superior (CAPES). We are also grateful to Central Analítica (UFC).

\section{References}

1. Cosgrove, W. J.; Rijsberman, R.; World Water Vision; Earthscan Publications: London, UK, 2000.

2. Hochmuth, H.; Thevs, N.; He, P.; Environ. Earth Sci. 2015, 73, 5269.

3. Chandrika, K. S. V. P.; Singh, A.; Sarkar, D. J.; Rathore, A.; Kumar, A.; J. Appl. Polym. Sci. 2014, 41060, 1.

4. Montesano, F. F.; Parente, A.; Santamaria, P.; Sannino, A.; Serio, F.; Agr. Agr. Sci. Procedia 2015, 4, 451.

5. Cannazza, G.; Cataldo, A.; De Benedetto, E.; Demitri, C.; Madaghiele, M.; Sannino, A.; Water 2014, 6, 2056.

6. Kalaleh, H.-A.; Tally, M.; Atassi, Y.; Polym. Sci., Ser. B 2015, 57, 750 .

7. Leitão, R. C. F.; de Moura, C. P.; da Silva, L. R. D.; Ricardo, N. M. P. S.; Feitosa, J. P. A.; Muniz, E. C.; Fajardo, A. R.; Rodrigues, F. H. A.; Quim. Nova 2015, 38, 370.

8. Magalhães, A. S. G.; Almeida Neto, M. P.; Bezerra, M. N.; Feitosa, J. P. A.; J. Braz. Chem. Soc. 2013, 24, 304.

9. Li, P.; Kim, N. H.; Siddaramaiah, J. H. L.; Composites, Part B 2009, 40, 275.

10. Cândido, J. S.; Pereira, A. G. B.; Fajardo, A. R.; Ricardo, N. M. P. S.; Feitosa, J. P. A.; Muniz, E. C.; Rodrigues, F. H. A.; Composites, Part B 2013, 51, 24653.

11. Li, Y.; Xin, S.; Bian, Y.; Xu, K.; Han, C.; Dong, L.; Int. J. Biol. Macromol. 2016, 85, 63.

12. Food and Agriculture Organization of the United Nations (FAO); http://www.fao.org/faostat/en/\#compare, accessed on March 6, 2017.

13. Oliveira, D. A.; Benelli, P.; Amante, E. R.; J. Cleaner Prod. 2013, 46, 42.

14. Rossi, M.; Nys, Y.; Anton, M.; Bain, M.; De Ketelaere, B.; de Reu, K.; Dunn, I.; Gautron, J.; Hammershøj, M.; Hidalgo, A.; Meluzzi, A.; Mertens, K.; Nau, F.; Sirri, F.; World's Poultry Sci. J. 2013, 69, 414.

15. Tiimob, B. J.; Jeelani, S.; Rangari, V. K.; J. Appl. Polym. Sci. 2016, 133, 43124 .
16. Demirel, M.; Aksakal, B.; J. Sol-Gel Sci. Technol. 2016, 78, 126.

17. Tan, Y. H.; Abdullah, M. O.; Hipolito, C. N.; Yap, Y. H. T.; Appl. Energy 2015, 160, 58.

18. Baláž, M.; Ficeriová, J.; Briančin, J.; Chemosphere 2016, 146, 458.

19. Elabbas, S.; Mandi, L.; Berrekhis, F.; Pons, M. N.; Leclerc, J. P.; Ouazzani, N.; J. Environ. Manage. 2016, 166, 589.

20. Soares, M. A. R.; Quina, M. J.; Ferreira, R. M. Q.; J. Environ. Manage. 2015, 164, 137.

21. Yew, M. C.; Ramli Sulong, N. H.; Yew, M. K.; Amalina, M. A.; Johan, M. R.; Prog. Org. Coat. 2015, 81, 116.

22. Magalhães, A. S. G.; Almeida Neto, M. P.; Bezerra, M. N.; Ricardo, N. M. P. S.; Feitosa, J. P. A.; Quim. Nova 2012, 35, 1464.

23. Lindroos, A.-J.; Brügger, T.; Derome, J.; Derome, K.; Water, Air, Soil Pollut. 2003, 149, 269.

24. Ludwig, B.; Khanna, P. K.; Raison, R. J.; Jacobsen, K. L.; Forest Ecol. Manage. 1998, 103, 9.

25. Hammecker, C.; van Asten, P.; Marlet, S.; Maeght, J.-L.; Poss, R.; Geoderma 2009, 150, 129.

26. Khemthong, P.; Luadthong, C.; Nualpaeng, W.; Changsuwan, P.; Tongprem, P.; Viriya-Empikul, N.; Faungnawakij, K.; Catal. Today 2012, 190, 112.

27. Xu, B.; Toffolo, M. B.; Regev, L.; Boaretto, E.; Poduska, K. M.; Anal. Methods 2015, 7, 9304.

28. Al-Hosney, H. A.; Grassian, V. H.; Phys. Chem. Chem. Phys. 2005, 7, 1266.

29. Papageorgiou, S. K.; Kouvelos, E. P.; Favvas, E. P.; Sapalidis, A. A.; Romanos, G. E.; Katsaros, F. K.; Carbohydr. Res. 2010 , $345,469$.

30. Li, S.; Leroy, P.; Heberling, F.; Devau, N.; Jougnot, D.; Chiaberge C.; J. Colloid Interface Sci. 2016, 468, 262.

31. Dassanayake, N. L.; Phillips, R. W.; Anal. Chem. 1984, 56, 1753.

32. Silva, M. E. S. R.; Dutra, E. R.; Mano, V.; Machado, J. C.; Polym. Degrad. Stab. 2000, 67, 491.

33. Ramazani-Harandi, M. J.; Zohuriaan-Mehr, M. J.; Yousefi, A. A.; Ershad-Langroudi, A.; Kabiri, K.; J. Appl. Polym. Sci. 2009, 113, 3676.

34. Santiago, F.; Mucientes, A. E.; Osorio, M.; Poblete, F. J.; Polym. Int. 2006, 55, 843.

35. Diez-Peña, E.; Quijada-Garrido, I.; Barrales-Rienda, J. M.; Macromolecules 2002, 35, 8882.

36. Zheng, Y.; Li, P.; Zhang, J.; Wang, A.; Eur. Polym. J. 2007, 43, 1691.

Submitted: October 17, 2016

Published online: March 9, 2017 